\title{
Five-year Survival After Surgical Removal and Gamma Knife Stereotactic Radiosurgery for a Cerebellar Metastasis from an Esophagogastric Junction Cancer: A Case Report and Literature Review
}

\author{
YOSHIKAZU KANAZAWA ${ }^{1}$, ITSUO FUJITA ${ }^{1}$, DAISUKE KAKINUMA ${ }^{1}$, YUTO AOKI $^{1}$, \\ HITOSHI KANNO ${ }^{1}$, HIROKI ARAI ${ }^{1}$, KUNIHIKO MATSUNO ${ }^{1}$, TOMOHIRO SHIMODA ${ }^{1}$, \\ TAKESHI MATSUTANI ${ }^{1}$, NOBUTOSHI HAGIWARA ${ }^{1}$, TSUTOMU NOMURA $^{1}$, \\ TAKESHI YAMADA $^{1}$, SHUNJI KATO ${ }^{1}$, ZENYA NAITO $^{2}$, HIDEAKI TAKASAKI $^{3}$ and EIJI UCHIDA ${ }^{1}$ \\ Departments of ${ }^{1}$ Gastrointestinal and Hepato-biliary-pancreatic Surgery, and \\ ${ }^{2}$ Pathology, Nippon Medical School, Tokyo, Japan; \\ ${ }^{3}$ Department of Surgery, Kamisu Saiseikai Hospital, Kamisu, Japan
}

\begin{abstract}
Brain metastases originating from esophageal or gastric cancer are rare, accounting for 2.1-3.3\% of all brain tumors registered in Japan. There are no established therapeutic measures for brain metastases, which accordingly have a poor prognosis. We present here a patient who survived for 5 years after surgery and gamma knife treatment of a cerebellar metastasis from esophagogastric adenocarcinoma. The primary gastric cancer was treated by laparotomy with total gastrectomy, splenectomy, and D2 lymphadenectomy. It was diagnosed as a esophagogastric junction Siewert type II tumor, type 3, tub1-2, pT3 (SS), pN1, and stage IIB on histopathological examination of the surgical specimen. Five months postoperatively, a solitary cerebellar metastasis was identified and surgically removed, followed by 20 Gy administered by gamma knife stereotactic radiosurgery; the patient received no subsequent treatment such as chemotherapy. Five years after the primary surgery, there have been no recurrences and the patient has a good quality of life. There are very few case reports of long-term survival after surgical treatment of cerebellar metastases
\end{abstract}

This article is freely accessible online.

Correspondence to: Yoshikazu Kanazawa, Department of Gastrointestinal and Hepato-biliary-pancreatic Surgery, Nippon Medical School, 1-1-5, Sendagi, Bunkyo-ku, Tokyo 113-8603, Japan. Tel: +81 338222131, Fax: +81 356850989, e-mail: kanazawa-y@nms.ac.jp

Key Words: Esophagogastric junction cancer, gastric cancer, brain metastasis, stereotactic radiosurgery, gamma knife, long-term survival. from esophagogastric junction cancer. We report our experience and review published case reports of surgical treatment of brain metastases from gastric cancer.

Brain metastases from esophageal or gastric cancer account for approximately $2.1-3.3 \%$ of all brain tumors registered in Japan (1). Their prognosis is poor because there are no established therapeutic strategies (2). Here, we report a patient who survived for 5 years after treatment of a solitary cerebellar metastasis from cancer of the esophagogastric junction (EGJ) and review published case reports.

\section{Case Report}

The patient, a 74-year-old woman who was $159.5 \mathrm{~cm}$ tall and weighed $45.5 \mathrm{~kg}$, was diagnosed with advanced EGJ cancer and underwent total gastrectomy with splenectomy and D2 lymph node dissection. After an uncomplicated postoperative period, the patient was discharged from hospital on postoperative day 12. The primary EGJ cancer was diagnosed as Siewert type II, type 3 by pathological examination of the excised surgical specimen. Findings included type 3 , tumor size $70 \times 50 \mathrm{~mm}$, moderately differentiated tubular adenocarcinoma, ss, ly1, v2, two lymph node metastases, and stage IIB according to the Japanese Classification of Gastric Carcinoma (3) (Figures 1 and 2). Six weeks postoperatively, the patient commenced adjuvant chemotherapy with $120 \mathrm{mg} / \mathrm{kg}$ of S-1. However, she developed grade 2 anorexia and systemic malaise according to Common Terminology Criteria for Adverse Events (CTCAE) version 4.0 (4), and therefore discontinued this treatment after 2 weeks, refused alternative chemotherapy and was only followed-up. 
Five months after her first presentation, the patient was urgently hospitalized for dizziness, double vision, and anarthria. An emergency brain computed tomographic scan revealed a $17-\mathrm{mm}$ high-density nodule in the left cerebellar hemisphere and a pustular lesion anterior to it with associated hydrocephalus (Figure 3). In addition, a brain magnetic resonance imaging revealed an irregularly enhancing $16 \times 10 \mathrm{~mm}$ tumor with T2 low intensity (Figure 4a) and T1 high intensity signals (Figure 4b). The tumor was confidently diagnosed as a brain metastasis. On cerebrospinal fluid analysis, the tumor was judged as class II but without meningeal dissemination.

The cerebellar metastasis was removed via a craniotomy by neurosurgeons. The operation time was 3 hours 32 minutes and blood loss $85 \mathrm{ml}$ and there were no surgical complications. Findings on pathological examination of the surgical specimen were as follows: moderately differentiated adenocarcinoma with necrotic areas and of similar morphology to the previously excised primary adenocarcinoma (Figure 5a); no cancer cells were detected at the resection margins. On immunostaining using antibodies for cytokeratin 7 (CK7) and CK20, the surgical specimen was negative for CK7 and positive for CK20, indicating that the metastasis had originated from the gastrointestinal tract (Figure 5b and c). The final diagnosis was thus cerebral metastasis from gastric cancer. After an uncomplicated postoperative period, the patient was transferred to a different hospital on postoperative day 28 and treated with stereotactic radiosurgery (SRS) using a gamma knife at a dose of 20 Gy to the surgical margins. Thereafter the patient underwent systemic surveillance every 6 months. Five years after removal of the cerebellar tumor and radiosurgery, the patient is asymptomatic and has no evidence of recurrence.

\section{Discussion}

The incidence of EGJ cancer in Japan has recently been increasing $(5,6)$; however, there are few reports on brain metastases from esophageal or gastric cancer or on the longterm prognosis of advanced gastric cancer with brain metastasis after surgical treatment. We here report long-term survival of 5 years by surgical treatment and radiotherapy for brain metastasis of advanced gastric cancer.

From 2001-2004, 17.8\% of all brain tumors in Japan were metastases. The most commonly responsible primary tumors were lung cancer at $45.6 \%$, cancer of the upper digestive tract such as esophageal and gastric cancer accounting for only $2.1-3.3 \%$ (1). Additionally, most patients diagnosed with brain metastasis from gastric cancer are in the terminal stage. York et al. reported finding brain metastases in 24 $(0.7 \%)$ of the 3,320 patients evaluated; all 24 also had metastases in other organs, were treated with best supportive care only, and had very poor prognoses (2). Thus, there are

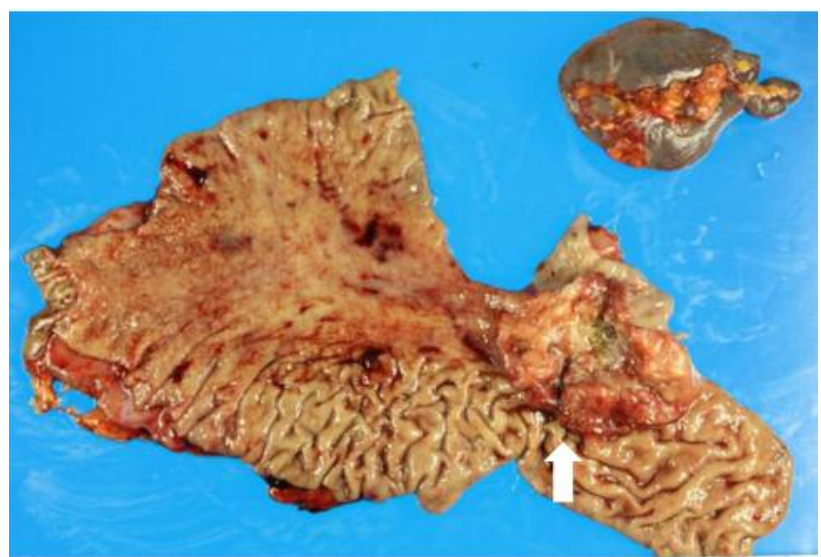

Figure 1. Surgical specimen: primary tumor. Type 3 tumor in the esophagogastric junction (white arrow).

no established treatments for brain metastases and no published reports discussing surgical resection and long-term survival patients with brain metastatic lesions in detail as far as we are aware. We therefore reviewed published reports concerning surgical treatment of brain metastases from gastric cancer.

A search of PubMed yielded only 17 reports on surgical resection of brain metastases from gastric or EGJ cancer published between 1990 and 2016 in Japan, including those by Kasakura et al. (7), Matsunaga et al. (8), and others. We summarize 20 published surgical cases, including these reports from Japan and our case (7-20) (Table I). Metastatic foci were surgically resected and histologically confirmed as metastases in all of these patients. They comprised of 16 men and four women with a median age of 67.5 (30-79) years. The primary foci were in the EGJ or upper part of the stomach, including the $U$ region, in 8/13 patients, and histological examination showed tubular, poorly differentiated and papillary adenocarcinomas in nine, five, and three patients, respectively (3). Thus, many of the primary lesions were in the upper stomach, including the EGJ. The degree of differentiation varied considerably.

Gastric cancer is believed to metastasize to the brain via the following three routes: i) the portal venous system via the liver and lungs; ii) from the lymphatic nodes surrounding the primary focus into the spinal subarachnoid space via nerve roots; and iii) via the vertebral vein directly through to the brain, without passing through the liver or lungs. Of these routes, the third is considered most likely for cerebellar metastases i.e. through the vertebral venous system via the esophageal and azygos vein anastomoses with the internal jugular venous system, and via the transverse sinus, which has many anastomoses with the cerebellar venous system (21). Accordingly, the metastatic pathway in the present case 

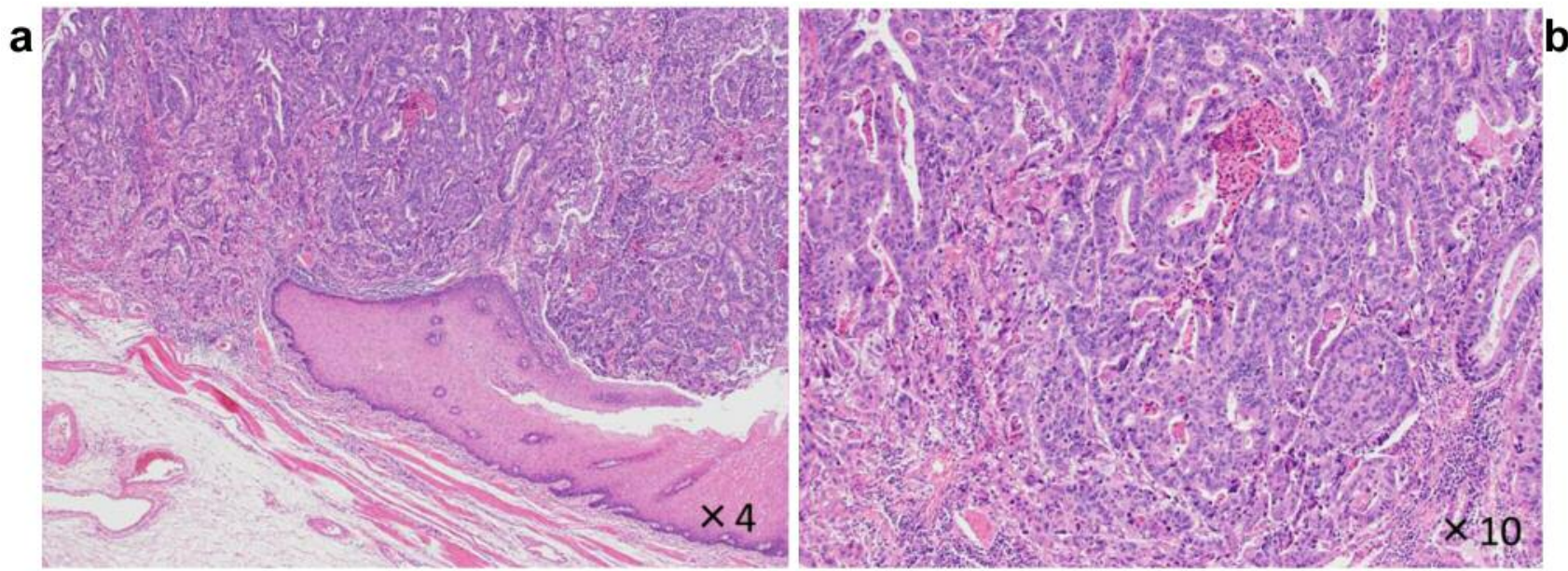

Figure 2. Photomicrograph of the primary focus. The primary lesion in the esophagogastric junction is a moderately differentiated tubular adenocarcinoma.

was possibly from the esophageal vein to the vertebral venous system via the azygos vein because the primary lesion was in the upper part of the stomach with esophageal invasion. In other words, a single brain metastasis from cancer of the EGJ can occur via a specific route in the absence of metastasis to other organs.

The sites of metastasis were the cerebrum in nine of the reported patients and the cerebellum in 10 , with some overlap. The median interval between the initial operation and diagnosis of brain metastases was 11 (0-132) months; the intervals were short ( $<6$ months $)$ in four patients, including two treated at our Institution. All patients who survived over 3 years after resection of brain metastases were reported after 2003. These findings suggest that brain imaging should be performed before initiating treatment of these cancers.

In a randomized comparison study involving patients with a single metastatic brain tumor, Patchell et al. found that the mean survival time after tumor removal alone compared with tumor removal plus whole-brain radiation therapy (WBRT) was 15 versus 40 weeks and the local recurrence rates were $52 \%$ versus $20 \%$, respectively (22), indicating that tumor removal plus WBRT is superior. WBRT is considered highly effective in preventing recurrence and is also useful as adjuvant therapy. On the basis of these results, authorities in the USA and Europe recommend both tumor removal and WBRT as the first-line or standard therapy for solitary brain metastases. Meanwhile, means of preventing cognitive retention disorder, a delayed adverse event of WBRT, have not yet been established. Mintz et al. have stated that WBRT is difficult to administer and ineffective at controlling disease in patients with brain metastases (23).

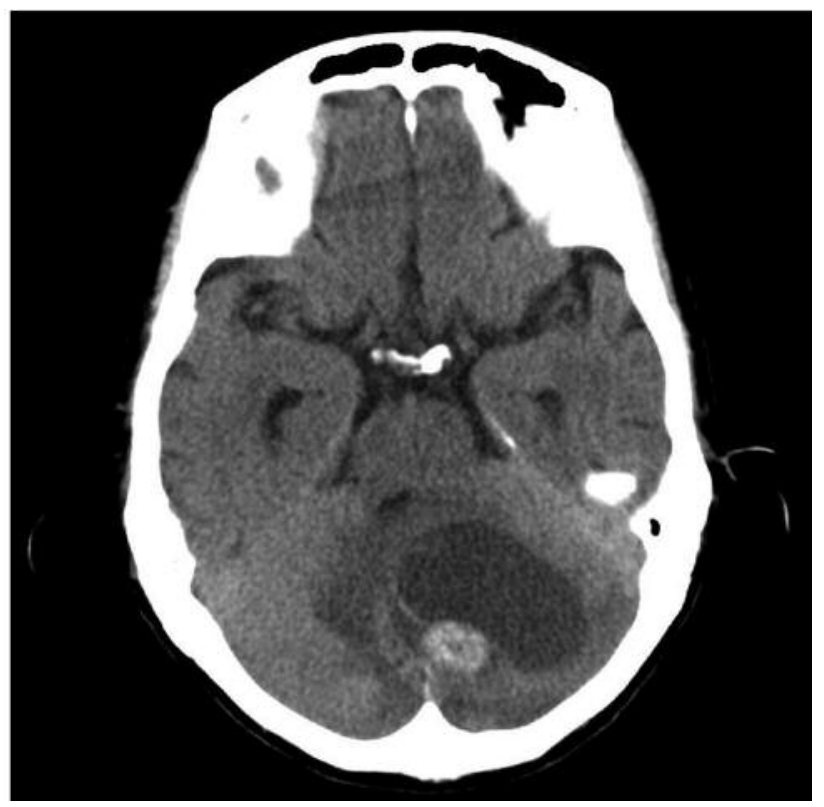

Figure 3. Brain computed tomographic image. A 17-mm high-density nodule in the left hemisphere of the cerebellum with a pustular lesion lying anteriorly is evident.

In recent years, with advances in SRS, including gamma knife and cyber knife, there have been more reports on the efficacy of SRS for brain metastases. Although the indications for SRS are limited to two or three brain metastases of diameter of $4 \mathrm{~cm}$ or less, it is superior to conventional surgical treatment with respect to treatment time and quality of life (24-27). In Japan, surgical resection 

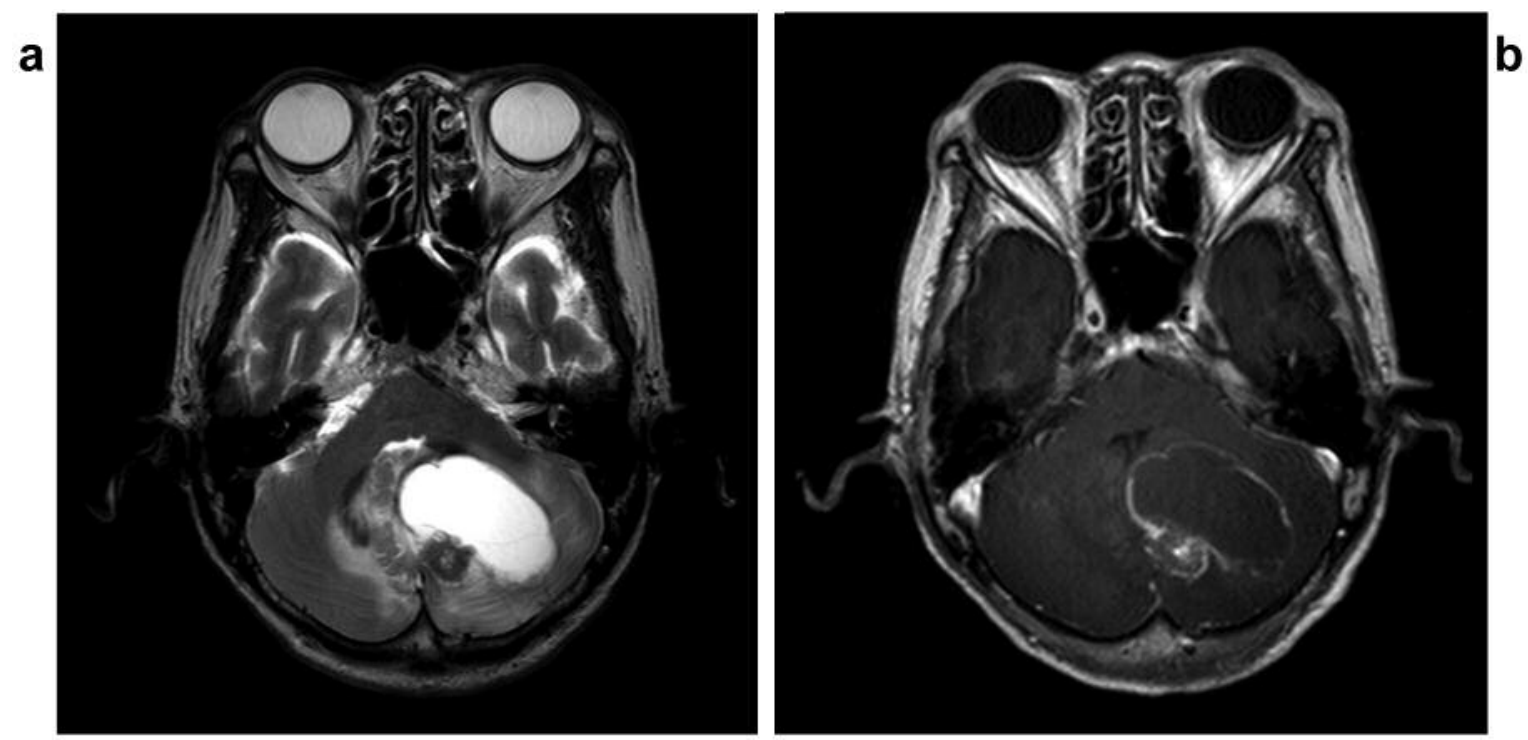

Figure 4. Brain magnetic resonance imaging. a: A $16 \times 10 \mathrm{~mm}$ tumor with T2 low-intensity signal in the left hemisphere of the cerebellum. $b$ : The same tumor with T1 high-intensity signal and irregular enhancement is evident.

Table I. Reports on patients with brain metastases from gastric cancer treated by surgical resection in Japan.

\begin{tabular}{|c|c|c|c|c|c|c|c|c|c|c|c|}
\hline \multirow[b]{2}{*}{ Case } & \multirow[b]{2}{*}{ Report } & \multirow[b]{2}{*}{$\begin{array}{c}\text { Report } \\
\text { year }\end{array}$} & \multirow[b]{2}{*}{$\begin{array}{c}\text { Age } \\
\text { (years) }\end{array}$} & \multirow[b]{2}{*}{ Gender } & \multicolumn{2}{|c|}{ Primary tumor } & \multirow[b]{2}{*}{$\begin{array}{c}\text { Interval } \\
\text { between initial } \\
\text { operation } \\
\text { and brain } \\
\text { metastasis } \\
\text { (months) }\end{array}$} & \multirow[b]{2}{*}{$\begin{array}{l}\text { Metastatic } \\
\text { site }\end{array}$} & \multirow[b]{2}{*}{$\begin{array}{l}\text { Number } \\
\text { of } \\
\text { metastasis }\end{array}$} & \multirow[b]{2}{*}{$\begin{array}{l}\text { Treatment } \\
\text { for } \\
\text { metastasis }\end{array}$} & \multirow[b]{2}{*}{$\begin{array}{r}\text { Survival } \\
\text { after brain } \\
\text { metastasis } \\
\text { (months) }\end{array}$} \\
\hline & & & & & Location & $\begin{array}{l}\text { Histological } \\
\text { type }\end{array}$ & & & & & \\
\hline 1 & Nagahori, et al. (10) & 1990 & 62 & Male & $\mathrm{U}$ & tub1 & 26.0 & Cerebrum & Solitary & Surgery, WBRT & 3 \\
\hline 2 & & 1990 & 61 & Male & UM & por & 19.0 & Cerebrum & Solitary & Surgery, WBRT & 28 \\
\hline 3 & Goda, et al. (9) & 1992 & 66 & Male & M & pap & 0.0 & Cerebellum & Solitary & Surgery & ND \\
\hline 4 & Iyobe, et al. (11) & 1993 & 63 & Female & $\mathrm{U}$ & por & 0.0 & Cerebellum & Solitary & Surgery, CT & 3 \\
\hline 5 & Iwasa, et al. (12) & 1999 & 69 & Female & $\mathrm{U}$ & tub1 & 36.0 & Cerebrum & Solitary & Surgery & 7 \\
\hline 6 & Kasakura, et al. (7) & 2000 & 53 & Male & ND & tub1 & 3.8 & ND & Solitary & Surgery, CT & 6 \\
\hline 7 & & 2000 & 59 & Male & ND & por & 12.0 & ND & Solitary & Surgery, CT & 3 \\
\hline 8 & & 2000 & 74 & Male & ND & tub1 & 18.0 & ND & Solitary & Surgery, WBRT & 7 \\
\hline 9 & Hayashi, et al. (13) & 2002 & 71 & Male & EGJ & tub2 & 132.0 & Cerebrum & Solitary & Surgery, SRS, CT & 2 \\
\hline 10 & Noguchi, et al. (14) & 2003 & 75 & Male & $\mathrm{L}$ & tub1 & 15.0 & Cerebrum & Solitary & Surgery & 60 \\
\hline 11 & Kitayama, et al. (15) & 2006 & 76 & Male & ND & por & 5.0 & Cerebrum & Solitary & Surgery, SRS & 12 \\
\hline 12 & Matsubara, et.al. (16) & 2008 & 72 & Male & MU & tub1 & 8.0 & Cerebellum & Solitary & Surgery, CT & 45 \\
\hline 13 & Tamura, et al. (17) & 2011 & 76 & Male & ND & ND & 24.0 & Cerebellum & ND & Surgery & 26 \\
\hline 14 & & 2011 & 57 & Male & ND & ND & 11.0 & $\begin{array}{l}\text { Cerebrum, } \\
\text { cerebellum }\end{array}$ & Multiple & Surgery, SRS & 12 \\
\hline 15 & Yunoki, et al. (18) & 2013 & 79 & Male & ND & ND & 21.0 & Cerebellum & Solitary & Surgery, SRS & 54 \\
\hline 16 & Matsunaga, et al. (8) & 2013 & 71 & Male & EGJ & tub2 & 6.0 & Cerebrum & Solitary & Surgery, SRS, CT & T 66 \\
\hline 17 & & 2013 & 64 & Male & EGJ & pap & 4.0 & Cerebrum & Solitary & Surgery, SRS & 48 \\
\hline 18 & Kawano, et al. (19) & 2015 & 62 & Male & M & por & 3.0 & Cerebellum & Solitary & Surgery & 120 \\
\hline 19 & Maezawa et al. (20) & 2016 & 30 & Female & $\mathrm{U}$ & pap & 11.0 & Cerebellum & Solitary & Surgery, CT & 72 \\
\hline 20 & Current study & 2017 & 74 & Female & EGJ & tub2 & 4.0 & Cerebellum & Solitary & Surgery, SRS & 60 \\
\hline
\end{tabular}

CT: Chemotherapy, EGJ: esophagogastric junction, ND: not described, pap: papillary adenocarcinoma, por: poorly differentiated adenocarcinoma, SRS: stereotactic radiosurgery, tub: tubular adenocarcinoma, WBRT: whole-brain radiation therapy. 


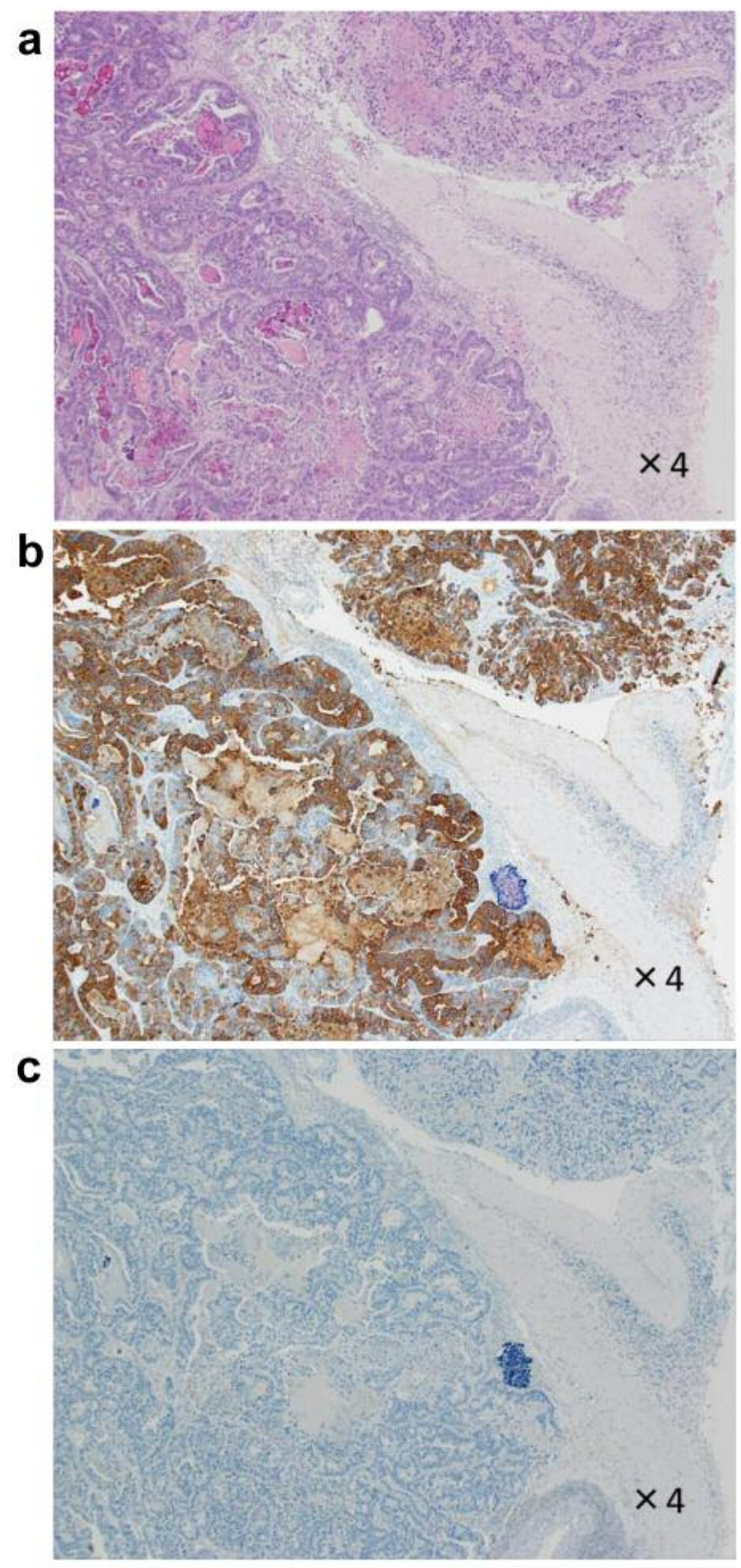

Figure 5. Photomicrographs of brain metastasis. a: The brain metastasis was found to be a well-to-moderately-differentiated tubular adenocarcinoma identical to the primary focus (hematoxylin and eosin stain). b: Positive staining for cytokeratin 20. $c$ : Negative staining for cytokeratin 7 staining.

alone, resection followed by WBRT, SRS only, chemotherapy only, and SRS plus chemotherapy were given to five, three, five, five, and two patients, respectively. Four out of the eight patients who survived for 3 years or beyond had undergone both surgery and SRS.
In patients with a solitary metastatic focus, as in the present patient, surgery and SRS resulted in long-term survival. Immediate investigation and intervention are essential to prevent worsening of neurological symptoms. In brief, surgical management of solitary metastatic lesions is the best treatment option in emergency situations. The patient presented in this report remains free of neurological symptoms and with good quality of life 5 years after her initial surgery and has no evidence of relapse.

\section{Conclusion}

We herein report a patient who has survived 5 years after treatment of a solitary cerebellar metastasis from EGJ cancer. In patients with advanced cancer of the upper stomach, screening for brain metastases should be considered both pre- and post-operatively. In patients with a solitary brain metastasis from gastric cancer, surgical removal with/without SRS treatment, including gamma knife, provide the strongest possibility of long-term survival and favorable quality of life.

\section{Conflict of Interest}

There are no financial or other relations that could lead to a conflict of interest in regard to this study.

\section{Informed Consent}

The patient gave informed consent for publication of her clinical details.

\section{References}

1 Committee of Brain Tumor Registry of Japan: Report of Brain Tumor Registry of Japan, 2001-2004. Neurol Med Chir 54: 1101, 2014.

2 York JE, Stringer J, Ajani JA, Wildrick DM and Gokaslan ZL: Gastric cancer and metastasis to the brain. Ann Surg Oncol 6: 771-776, 1999.

3 JAPANESE Gastric Cancer Association. Japanese Classification of Gastric Carcinoma: Third English Edition. Gastric Cancer 14: 101-112, 2011.

4 Chen AP, Setser A, Anadkat MJ, Cotliar J, Olsen EA, Garden BC and Lacouture ME: Grading dermatologic adverse events of cancer treatments: the Common Terminology Criteria for Adverse Events Version 4.0. J Am Acad Dermatol 67: 10251039, 2012.

5 Siewert JR and Stein HJ: Carcinoma of the cardia: carcinoma of the gastro-esophageal junction - classification, pathology and extent of resection. Dis Esophagus 9: 173-182, 1996.

6 Kusano C, Gotoda T, Khor CJ, Katai H, Kato H, Taniguchi H and Shimoda T: Changing trends in the proportion of adenocarcinoma of the esophagogastric junction in a large tertiary referral center in Japan. J Gastroenterol Hepatol 23: 1662-1665, 2008.

7 Kasakura Y, Fujii M, Mochizuki F, Suzuki T and Takahashi T: Clinicopathological study of brain metastasis in gastric cancer patients. Surg Today 30(6): 485-490, 2000. 
8 Matsunaga M, Wada S, Daa T, Harada K, Okamura $\mathrm{K}$ and Noguchi T: Long-term survival after resection of brain metastases from esophagogastric junction adenocarcinoma: report of two cases and review of the literature. Clin J Gastroenterol 7(3): 213-218, 2014.

9 Goda K, Tsunoda S, Sakaki T, Morimoto T, Hashimoto H, Yoshimura $\mathrm{Y}$ and Horikawa: AFP-producing gastric cancer manifested by metastasis to the tentorium cerebelli; case report and review of the literature. No Shinkei Geka 20(2): 183-185, 1992.

10 Nagahori Y, Sekikawa T, Maeda Y, Ishikawa T, Noguchi A and Sugahara K: Two cases of brain metastasis of gastric cancer. J Jpn Surg Assoc 51(7): 1438-1442, 1990.

11 Iyobe T, Kawamura T, Shima Y, Sawasaki K, Haryo S, Fujita H, Kurauchi M, Fuji T and Okada E: Advanced gastric cancer revealed by cerebellar metastasis - A case report. Jpn J cancer Clin 39(8): 959-964, 1993.

12 Iwasa N, Akagi K, Matsumoto K, Abekura M, Maeda Y, Fukumoto $\mathrm{S}$ and Sung H: Recurrent cerebral hemorrhage caused by metastatic gastric cancer - A case report. Jpn J Cancer Clin 45(9): 993-997, 1999.

13 Hayashi Y, Kamata T ,Hayashi H, Minatoya G, Michiwa Y, Onishi I, Takeda T and Kanno M: A case of brain metastasis developing 11 years after resection for gastric remnant cancer with para-aortic lymph node metastasis. Jpn J Gastroenterol Surg 35(6): 608-611, 2002.

14 Noguchi J, Kitahara K, Date K, Ono K and Kawaguchi M: A long survival case of brain metastases from AFP producing gastric cancer. Jpn J Gastroenterol Surg 36(12): 1659-1664, 2003.

15 Kitayama Y, Yoden Y and Okamoto N: A Case of effective paclitaxel therapy for gastric cancer with brain metastasis. Jpn J Cancer Chemother 33(7): 981-984, 2006.

16 Matsubara T, Yoshizawa Y, Sasaya S, Sakuraba K, Shirahata A, Gotoh T, Maezawa K, Saito M, Nemoto H and Sanada Y: A long survival case of metachronous cerebellar metastasis that was caused by gastric cancer. Jpn J Gastroenterol Surg 41(1): 76-81, 2008 .

17 Tamura S, Takeno A, Miki H, Uchiyama C, Kanemura T, Ono H, Hamanaka M, Suzuki R, Nakahira S, Nakata K and Takeda Y: Clinical outcomes in patients with brain metastasis from gastric cancer. Jpn J Cancer Chemother 38(12): 2093-2096, 2011.

18 Yunoki M, Shimizu T, Matsumoto A, Nishida A, Hirashita H, Yoshino K, Kobayashi M, Mizobuchi K and Morito T: A case of metastatic cerebellar tumor from gastric cancer in which long-term survival was achieved. Curr Pract Neurosug 23(6): 682-687, 2013.
19 Kawano S, Kobayasgu A, Shibasaki H, Kinoshita T and Saito N: A case of long-term survival with a solitary cerebellar metastatic from gastric cancer. J Jpn Surg Assoc 76(4): 757-761, 2015.

20 Maezawa Y, Sato T, Kano K, Segami K, Nakajima T, Kawabe T, Shirai J, Fujikawa H, Aoyama T, Hayashi T, Ikeda K, Yamada T, Tsuchida S, Yamamoto N, Ohshima T, Rino Y, Masuda M, Ogata T, Cho $\mathrm{H}$ and Yoshikawa T: A case of long-term survival after gastrectomy and metachronous brain metastasis. Jpn J Chemother 43(10): 1286-1288, 2016.

21 Baston OV: The function of the vertebral veins and their role in the spread of metastases. Ann Surg 112: 138-149, 1940.

22 Patchell RA, Tibbs PA, Regine WF, Dempsey RJ, Mohiuddin M, Kryscio RJ, Markesbery WR, Foon KA and Young B: Postoperative radiotherapy in the treatment of single metastases to the brain: a randomized trial. JAMA 280(17): 1485-1489, 1998.

23 Mintz AP and Cairncross JG: Treatment of a single brain metastasis: the role of radiation following surgical resection. JAMA 280(17): 1527-1529, 1998

24 McDermott MW and Sneed PK: Radiosurgery in metastatic brain cancer. Neurosurg 57: 45-53, 2005.

25 Kondziolka D, Martin JJ, Flickinger JC, Friedland DM, Brufsky AM, Baar J, Agarwala S, Kirkwood JM and Lunsford LD: Longterm survivors after gamma knife radiosurgery for brain metastases. Cancer 104: 2784-2791, 2005.

26 Phillips MH, Stelzer KJ, Griffin TW, Mayberg MR and Winn HR: Stereotactic radiosurgery: a review and comparison of methods. J Clin Oncol 12: 1085-1099, 1994.

27 Muacevic A, Kreth FW, Horstmann GA, Schmid-Elsaesser R, Wowra B, Steiger HJ and Reulen HJ: Surgery and radiosurgery compared with gamma knife radiosurgery in the treatment of solitary cerebral metastases of small diameter. J Neurosurg 91: 35-43, 1999. 